\title{
B cell and/or autoantibody deficiency do not prevent neuropsychiatric disease in murine systemic lupus erythematosus
}

Jing Wen ${ }^{1}$, Jessica Doerner ${ }^{1}$, Samantha Chalmers ${ }^{1}$, Ariel Stock${ }^{1}$, Haowei Wang ${ }^{2}$, Maria Gullinello³, Mark J. Shlomchik ${ }^{4}$ and Chaim Putterman ${ }^{1,5^{*}}$

\begin{abstract}
Background: Neuropsychiatric lupus (NPSLE) can be one of the earliest clinical manifestations in human lupus. However, its mechanisms are not fully understood. In lupus, a compromised blood-brain barrier may allow for the passage of circulating autoantibodies into the brain, where they can induce neuropsychiatric abnormalities including depression-like behavior and cognitive abnormalities. The purpose of this study was to determine the role of B cells and/or autoantibodies in the pathogenesis of murine NPSLE.

Methods: We evaluated neuropsychiatric manifestations, brain pathology, and cytokine expression in constitutively (JhD/MRL/lpr) and conditionally (hCD20-DTA/MRL/Ipr, inducible by tamoxifen) B cell-depleted mice as compared to MRL/Ipr lupus mice.

Results: We found that autoantibody levels were negligible (JhD/MRL/lpr) or significantly reduced (hCD20-DTA/ MRL/Ipr) in the serum and cerebrospinal fluid, respectively. Nevertheless, both JhD/MRL/lpr and hCD20-DTA/MRL/ Ipr mice showed profound depression-like behavior, which was no different from MRL/lpr mice. Cognitive deficits were also observed in both JhD/MRL/lpr and hCD20-DTA/MRL/lpr mice, similar to those exhibited by MRL/lpr mice. Furthermore, although some differences were dependent on the timing of depletion, central features of NPSLE in the MRL/Ipr strain including increased blood-brain barrier permeability, brain cell apoptosis, and upregulated cytokine expression persisted in B cell-deficient and B cell-depleted mice.
\end{abstract}

Conclusions: Our study surprisingly found that B cells and/or autoantibodies are not required for key features of neuropsychiatric disease in murine NPSLE.

Keywords: Lupus, SLE, Neuropsychiatric SLE, B cells, Autoantibodies

\section{Background}

Neuropsychiatric lupus (NPSLE) is a debilitating manifestation of systemic lupus erythematous (SLE), with a prevalence of approximately $40 \%$ [1]. NPSLE manifestations include a broad spectrum of syndromes; headache, mood disorders, cognitive dysfunction, seizures, cerebrovascular diseases, and anxiety are the most common [2]. The pathogenesis of NPSLE is believed to be dependent upon whether the symptoms are focal or diffuse. Often,

\footnotetext{
* Correspondence: chaim.putterman@einstein.yu.edu

${ }^{1}$ Department of Microbiology and Immunology, Albert Einstein College of Medicine, Bronx, NY, USA

${ }^{5}$ Division of Rheumatology, Albert Einstein College of Medicine, F701N, 1300 Morris Park Ave, Bronx, NY 10461, USA

Full list of author information is available at the end of the article
}

focal events such as cerebrovascular disease and seizures are associated with anti-phospholipid antibody-related hypercoagulability and thrombosis, while diffuse deficits, including depression and cognitive impairment, are mediated by as of yet unclear inflammatory pathways [3]. NPSLE can occur at any stage of disease [4]. The treatment options available are limited, with most patients treated empirically with immunosuppressive agents, corticosteroids, or symptomatic therapy [3].

The mechanisms underlying diffuse NPSLE development are not well understood; however, autoantibodymediated brain damage and cytokine-induced CNS inflammation are believed to be important [5]. To date, several studies have examined whether specific subtypes 
of autoantibodies are involved in the pathogenesis (and can serve as biomarkers) of NPSLE. A role for antiribosomal $\mathrm{P}$ and anti-NMDA receptor autoantibodies in NPSLE has been proposed, but biomarker studies have not been entirely consistent [6]. Furthermore, while rituximab, an anti-CD20 monoclonal antibody used to deplete B cells in antibody-mediated diseases has shown some promise [7], a recent systematic review concluded that the evidence to date supporting its use in human NPSLE is relatively weak [8].

The MRL/lpr mouse strain is a validated murine lupus model, used extensively in the study of NPSLE [9]. Aside from the peripheral features such as autoantibody upregulation and severe kidney pathology, this strain also manifests cognitive deficits and depression-like behavior mimicking those found in human NPSLE [9]. Moreover, MRL/lpr mice exhibit an earlier onset of disease compared to NZB/W F1 and BXSB, and is one of the murine lupus strains with a greater prevalence of disease in females [9].

In order to investigate the potential role of $B$ cells and autoantibodies in NPSLE, we utilized a B cell depletion strategy in MRL/lpr mice. A previous study examined the efficacy of rituximab in the MRL/lpr strain and found that B cell depletion was difficult to achieve, though after prolonged treatment, nephritis was ameliorated; however, NPSLE was not evaluated [10]. Since antibody-mediated cell depletion is markedly impaired in lupus [10], we employed a genetic approach to assess the roles of B cells in NPSLE manifestations, using constitutively deficient (JhD/MRL/lpr) and conditionally B cell-depleted (hCD20-DTA/MRL/lpr) lupus-prone mice.

\section{Methods}

Mice

$\mathrm{JhD} / \mathrm{MRL} / \mathrm{lpr}$ mice were generated as described previously [11] and were maintained as a homozygous colony. Human CD20-TamCre/MRL/lpr mice were created by backcrossing human CD20-TamCre/C57BL/6J mice, which possess an insertion of an IRES-Tam-Cre cassette into the 3' UTR of the hCD20 locus [12], onto the MRL/lpr background (Jackson Laboratory, Bar Harbor, Maine) for more than seven generations. Human CD20-TamCre/MRL/lpr mice were maintained as heterozygotes via continuous breeding with MRL/lpr mice (Jackson Laboratory). Rosa26-Flox-Stop-DTA/MRL/lpr mice were generated by backcrossing Rosa26-Flox-Stop-DTA/C57BL/6J mice onto MRL/lpr mice for nine generations [13, 14]. The Rosa26Flox-STOP-DTA locus contains a gene for the diphtheria toxin $\alpha$ chain (DTA), and the expression of the toxin is inhibited in the presence of the STOP cassette. Rosa26Flox-Stop-DTA/MRL/lpr mice were maintained as homozygotes.
Human CD20-TamCre/MRL/lpr and Rosa26-FloxStop-DTA/MRL/lpr mice were crossed to generate the hCD20-TamCre-Rosa26-DTA/MRL/lpr (hCD20-DTA/ $\mathrm{MRL} / \mathrm{lpr}$ ) mice, a tamoxifen inducible conditional $\mathrm{B}$ cell-depleted strain. To induce B cell depletion, hCD20-DTA/MRL/lpr mice were treated with intraperitoneal tamoxifen $(0.2 \mathrm{mg} / \mathrm{g}$ weight $)$ every other day starting at the age of 14 weeks, for five injections in total. After the last injection, mice were bled the next day for serum IgG and anti-double stranded DNA IgG ELISA. After confirming the depletion of antibodies, animals were allowed to rest for 5 days before neurobehavioral testing.

The MRL/MPJ strain (Jackson Laboratory) is a congenic background control strain for MRL/lpr mice. Unlike MRL/lpr mice, MRL/MPJ mice carry a normal (unmutated) Fas gene, and therefore do not exhibit a substantial autoimmune diathesis until a much older age. Since MRL/ MPJ mice are genetically identical to MRL/lpr except in Fas, it is widely considered the most appropriate control for the latter lupus strain. At 4 months of age, while MRL/ lpr mice display neuropsychiatric manifestations including depression-like behavior and cognitive deficits with the upregulation of inflammatory mediators, MRL/MPJ mice demonstrate normal emotionality and cognitive function with baseline brain cytokine expression [15-17].

For all strains employed in these studies, when not all mice of a particular strain were used for a given experiment, a subset of mice was chosen randomly. All animals were handled according to the approved animal protocol at the Albert Einstein College of Medicine.

\section{Genotyping}

The detailed genotyping procedure for JhD/MRL/lpr mice by PCR was described previously [18]. For the human CD20-TamCre/MRL/lpr strain, positive litters were identified by the presence of Cre and ERT2 genes. The absence of the Rosa wild-type gene was used to screen for the Rosa26-Flox-Stop-DTA/MRL/lpr strain. The genotyping for these two strains was carried out by Transnetyx (Cordova, TN).

\section{Flow cytometry}

Peripheral blood was obtained from the hCD20-DTA/ $\mathrm{MRL} / \mathrm{lpr}$ and JhD/MRL/lpr mice. MRL/lpr mice were used as positive controls. Blood samples were first lysed in red blood cell (RBC) lysis buffer and washed with icecold $2 \%$ FBS. B cells were stained with anti-mouse CD19 conjugated to phycoerythrin (PE) for JhD/MRL/ lpr, or allophycocyanin (APC) (BD Bioscience, San Jose, CA) for hCD20-DTA/MRL/lpr (the YFP gene in the latter strain is incompatible with red fluorochromes). The percentage of CD19 positive cells was gated out of 
single cell lymphocyte populations by flow cytometry (FACScalibur, BD Bioscience).

\section{ELISA}

Anti-double stranded (ds) DNA antibodies in the serum and cerebrospinal fluid (CSF) were measured by ELISA, as previously described [19]. Total IgG in serum and CSF was measured by coating the plate with goat antimouse IgG (Southern Biotech, Birmingham, AL) overnight. Serum and CSF samples at a dilution of 1:500,000 and 1:500, respectively, were added to the plates for $2 \mathrm{~h}$. Plates were then incubated with alkaline phosphataseconjugated goat anti-mouse IgG (Southern Biotech) for $1 \mathrm{~h}$, and developed with phosphatase substrate.

In lupus, the standard method most commonly used to measure anti-NMDAR antibody titers in both murine models $[15,20]$ and human studies [21-23] is by ELISA. Serum anti-NMDA receptor IgG ELISA was performed by coating the plate with multimeric peptide DWEYSVWLSN at $20 \mu \mathrm{g} / \mathrm{ml}$, as described [15]. Serum samples were added to the plate at a dilution of 1:250 and detected with alkaline phosphatase-conjugated goat anti-mouse IgG (Southern Biotech). It is important, however, to recognize that using an ELISA-based method for measuring anti-NMDAR antibodies is not a standard neurological practice, and is not currently recommended for use in the clinical diagnosis of lupus.

\section{Neurobehavioral testing}

Comprehensive behavior testing, including the Porsolt swim test, open field, object placement, and object recognition tests, were conducted following the procedures described previously [19], and further detailed below. $\mathrm{JhD} / \mathrm{MRL} / \mathrm{lpr}$ mice were tested at 7-12 weeks of age and CD20-DTA/MRL/lpr mice were tested at 16-18 weeks of age, with separate age matched controls for each group. Mice were randomly selected for testing when not all mice in a given genotype were subjected to a particular neurobehavioral assessment.

\section{Porsolt swim test}

The Porsolt swim test is a standard and validated method used to evaluate depression-like behavior in rodents. Mice with depression-like behavior exhibit immobility, an indication of despair, while normal mice swim for the majority of the duration of the test. In the Porsolt swim test, each mouse was placed into a transparent cylindrical tank with water at $27^{\circ} \mathrm{C}$ for $10 \mathrm{~min}$. The first minute was not scored and in the following $9 \mathrm{~min}$, immobility was scored manually with stopwatches. Each subject was digitally recorded using Viewer III software. Total immobility (as \% total test duration) was calculated by the ratio of ([total time immobile in the water]/[total time scored] $) \times 100$. The scorers were blind to the experimental groups.

\section{Open field test}

The open field test was conducted in an arena $(40 \mathrm{~cm} \times$ $40 \mathrm{~cm} \times 40 \mathrm{~cm}$ ) with the center zone defined as $15 \mathrm{~cm} \times$ $15 \mathrm{~cm}$. General locomotor activity, including total track length, center track length, center time, and rears, were recorded by Viewer III software (Biobserve, Bonn, Germany) for $6 \mathrm{~min}$.

\section{Novel object placement and novel object recognition tests}

Object placement (OP) and object recognition (OR) tests were employed to assess spatial and visual recognition memory, respectively. In both tests, a training trial (trial 1 ) and a testing trial (trial 2) were conducted. In the $O P$ trial 1 , animals were given 5 min to explore two identical objects in different locations. After a 25-min retention interval, mice were returned to the same arena where one object was moved to a new location (trial 2). In the OR trial 1, animals were first allowed to explore two identical objects for $3 \mathrm{~min}$. After a 90-min retention interval, animals were tested in the same arena where one object was replaced with a novel object (trial 2). The experimenters were blind to the experimental groups. The preference score (\%) for object recognition and object placement tests was calculated as ([exploration time of the novel object (location)]/[exploration time of both objects (locations)]) $\times 100$. The cutoff to define "pass" in the object placement and object recognition tests was $53 \%[24,25]$.

\section{Brain histology}

Mice were sacrificed at 19 weeks of age. After extensive transcardial perfusing with cold PBS, the brains were dissected into right and left hemispheres. The right hemisphere of the brain was fixed in $4 \%$ paraformaldehyde (PFA) for $24 \mathrm{~h}$ at $4{ }^{\circ} \mathrm{C}$, and embedded in paraffin for sagittal sectioning. The left brain hemisphere including the region of the hippocampus was dissected, fixed in $4 \%$ PFA for $24 \mathrm{~h}$, followed by $30 \%$ sucrose at $4{ }^{\circ} \mathrm{C}$ overnight, and utilized for frozen sections in a coronal plane. The remaining brain tissue was snap-frozen for RNA extraction.

\section{Immunofluorescence}

For immunofluorescence staining, paraffin sections were incubated with mouse anti-glial fibrillary acidic protein (GFAP) (Millipore, Billerica, MA) or rabbit anti-mouse Iba1 (Chesterfield, VA) antibody, followed by donkey antimouse Alexa Fluor 594 or donkey anti-rabbit Alexa Fluor 488, respectively (Jackson ImmunoResearch, West Grove, PA). For albumin staining, paraffin sections were directly incubated with goat anti-mouse albumin-FITC (Alpha Diagnostic International, San Antonio, TX), and analyzed under a fluorescence microscope (Zeiss AxioObserver 
CLEM). Two sections were examined for each mouse brain. Quantitation of the intensity of Iba-1 and GFAP staining was performed by Image $\mathrm{J}$.

\section{TUNEL staining}

TUNEL staining was carried out by utilizing an in situ cell death detection kit-fluorescein (Roche, Indianapolis, IN) as described previously [26]. Slides were examined under a fluorescence microscope (Zeiss AxioObserver CLEM). One representative image was taken from each section, and the number of TUNEL positive cells in each section was counted. Two sections were analyzed for each mouse brain.

\section{Real-time PCR}

RNA was isolated from the brain of MRL/lpr, JhD/MRL/ lpr, hCD20-DTA/MRL/lpr, and MRL/MPJ mice at 19 weeks of age using RNEASY (Qiagen, Valencia, CA). Real-time PCR was performed in triplicate for selected genes including RANTES, MCP-5, IP-10, CXCL11, TNF, IFN $\beta$, IRF7, and IFIT1 as described [19]. The relative expression of each gene was normalized to GAPDH, and the mean relative expression of each gene in the control group (MRL/MPJ) was set to 1 .

\section{Statistical analysis}

Statistical analysis was performed by Graphpad Prism 6 software. Data are displayed as mean \pm standard error of the mean (SEM). The differences between two groups were calculated by an unpaired $t$ test (two tailed). Nonparametric and non-normally distributed data were analyzed by the Mann-Whitney test. Fisher's exact test was employed to compare the incidence of blood-brain barrier leakage between the two groups. Significance was considered as $p<0.05$.

\section{Results}

B cells, antibodies, and autoantibody levels are negligible (JhD/MRL/lpr) or significantly reduced (hCD20-DTA MRL/ Ipr) in the serum and CSF

To confirm B cell absence or depletion in JhD/MRL/lpr and hCD20-DTA/MRL/lpr mice, peripheral blood cells were stained for CD19 by flow cytometry. B cells were virtually absent in the JhD/MRL/lpr mice (Fig. 1a, upper right panel). Furthermore, a $\sim 90 \%$ reduction of $\mathrm{B}$ cells was observed in hCD20-DTA/MRL/lpr mice as compared to MRL/lpr mice (Fig. 1a, lower right panel). Confirming B cell deficiency in these strains, total IgG (Fig. 1b), anti-dsDNA IgG (Fig. 1c), and anti-NMDA receptor IgG (Fig. 1d) antibodies were virtually absent or significantly reduced in the serum and CSF of JhD/ MRL/lpr and hCD20-DTA/MRL/lpr mice, respectively.

\section{JhD/MRL/lpr and hCD20-DTA/MRL/lpr mice demonstrate} depression-like behavior and cognitive dysfunction One of the distinctive clinical features of human NPSLE is mood disorder, especially depression [5]. Previously, we and others reported that MRL/lpr mice display profound depression-like behavior, exhibited by excessive immobility in the forced swim test as an indicator of behavioral despair $[19,27]$. To investigate whether this depression-like behavior is B cell dependent, the Porsolt swim test was utilized in the B cell-deficient and B celldepleted MRL/lpr mouse models. Surprisingly, both JhD/MRL/lpr and hCD20-DTA/MRL/lpr mice exhibited markedly increased immobility (50-60\% floating time) in water as compared to the control MRL/MPJ mice (15-25\% floating time), and identical to wild-type MRL/ lpr mice (Fig. 2a). Thus, depression-like behavior persisted despite B cell deficiency or depletion in the MRL/ lpr strain.

Cognitive impairment is another common manifestation of NPSLE in both humans and MRL/lpr mice [9]. Autoantibodies such as IgG anti-ribosomal P and antiNMDA receptor have been suggested to play a role in cognitive deficits once the blood-brain barrier (BBB) is disrupted or circumvented [28, 29]. Thus, we investigated whether B cell-deficient or B cell-depleted lupus mice, which lack autoantibodies, would demonstrate cognitive dysfunction using object placement (spatial memory) and object recognition (visual memory) tests.

Mice preferentially explore novel objects and objects in novel locations. Thus, a failure to explore novel objects at greater than chance is an implicit measure of a failure to retain and/or recall the prior exposure to either an object or an object location, respectively, and is defined as cognitive (memory) impairment. JhD/MRL/ lpr mice manifested spatial memory impairment (Fig. 2b), while their recognition memory was intact (Fig. 2c). Although hCD20-DTA/MRL/lpr mice trended toward improved spatial memory performance compared to MRL/ lpr mice, the differences did not reach significance (Fig. 2b, right panel). hCD20-DTA/MRL/lpr mice did, however, exhibit cognitive deficits in the visual memory test (Fig. 2c). Our results suggest that, overall, evidence for cognitive dysfunction was present both for B celldeficient or B cell-depleted MRL/lpr mice.

\section{JhD/MRL/Ipr mice display increased general locomotion activity}

Open field tests were carried out to assess locomotor and exploratory activity in B cell-deficient and B celldepleted mice. Significantly increased total track length and number of rears were observed in JhD/MRL/lpr mice, indicating enhanced motor activity and exploration, respectively (Fig. 3a, b). hCD20-DTA/MRL/lpr mice, however, displayed behavior similar to MRL/lpr 
a
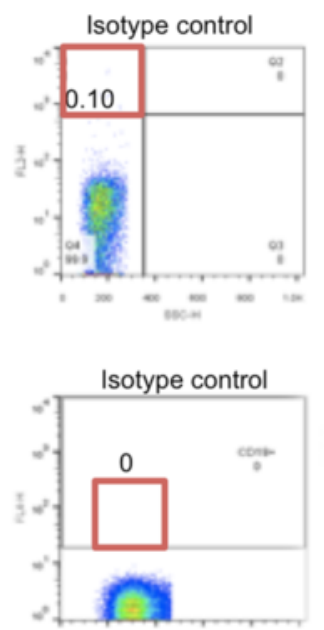

b Total $\lg G$ (serum)

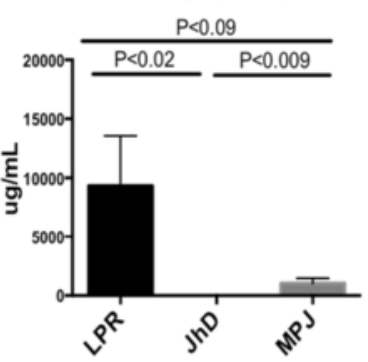

C
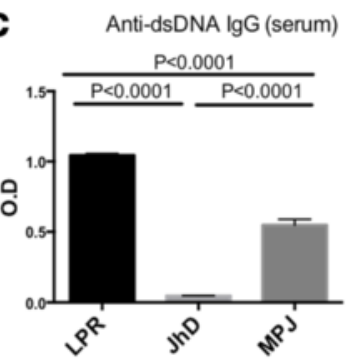

d

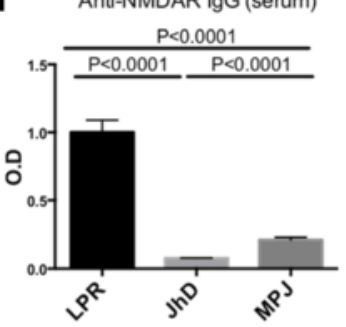

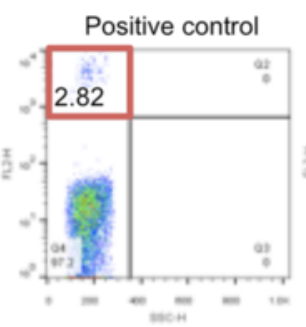
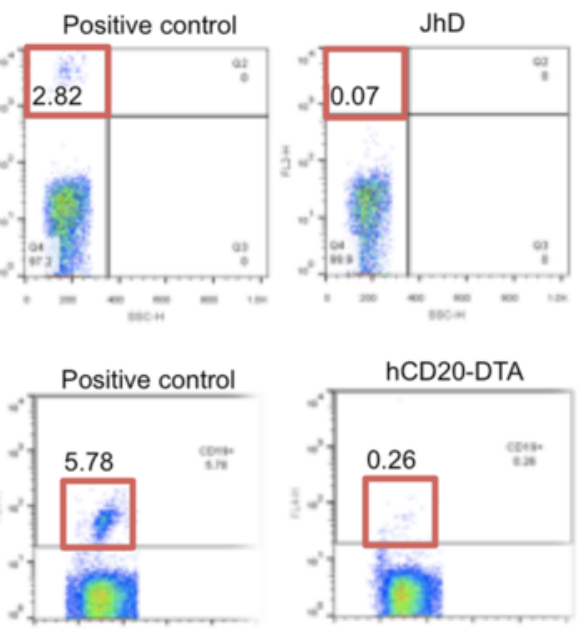

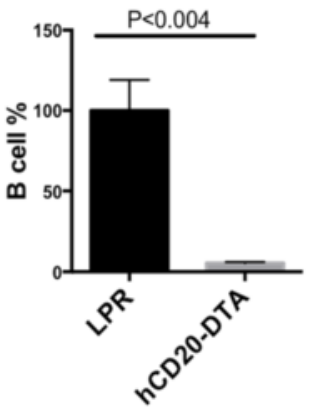

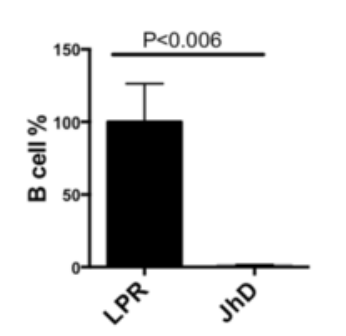
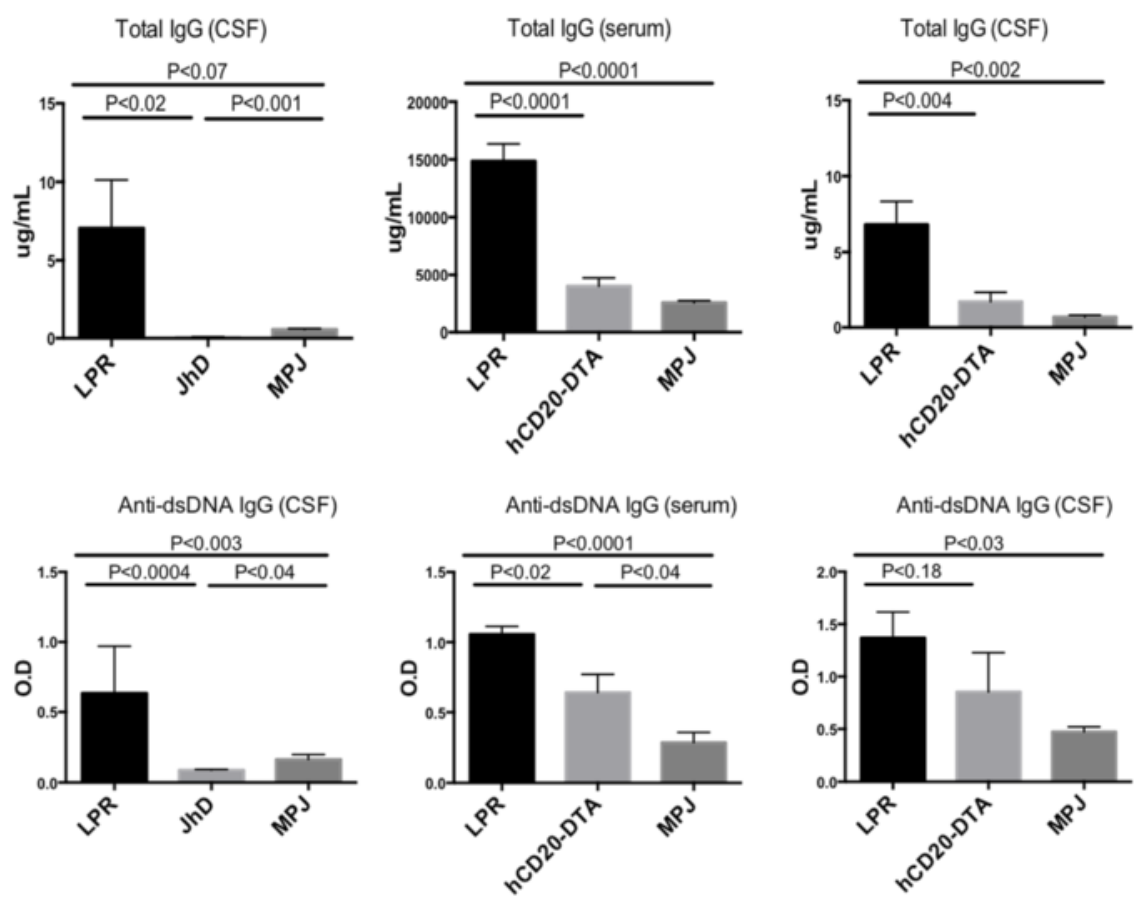

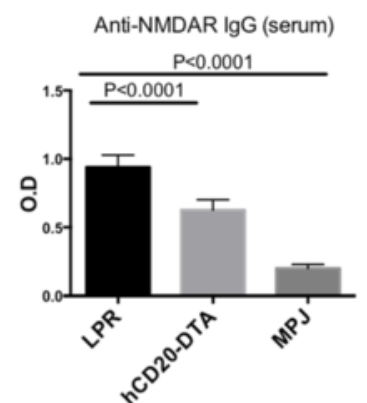

Fig. 1 (See legend on next page.) 
(See figure on previous page.)

Fig. 1 B cell counts and antibody titers are markedly reduced in the serum and CSF of JhD/MRL/lpr and hCD20-DTA/MRL/Ipr mice. FACS analysis of CD19 positive cells in the peripheral blood of JhD/MRL/lpr and hCD20-DTA/MRL/lpr mice is shown in (a). The \% CD19+ cells is provided in the red box in each panel. The MRL/Ipr strain is used as a positive control. Total lgG levels (b) and anti-dsDNA IgG titers (c) in the serum and CSF of JhD/MRL/lpr and hCD20/MRL/lpr were measured by ELISA. Anti-NMDA receptor antibodies in the serum of JhD/MRL/lpr and hCD20-DTA/MRL/Ipr mice are shown in (d). (JhD and control mice at 12-15 weeks of age: LPR mice, $n=5-8$; JhD mice, $n=5-8$; MPJ mice, $n=5-8$; hCD20-DTA and control mice at 15 weeks of age: LPR mice, $n=7$; hCD20-DTA mice, $n=7$; MPJ mice, $n=7$; except for the CSF ELISA experiments, where the number of mice in the LPR, hCD20-DTA , and MPJ group were 7, 4, and 4, respectively). The CSF ELISA was done once; all other experiments were repeated twice, with similar results

mice (Fig. 3a, b). The open field test can also assess riskseeking behavior, as measured by the amount of time spent, or distance travelled, in the center of the testing arena. Interestingly, MRL/lpr and JhD/MRL/lpr mice demonstrated an increase in the center track length, relative center track length (center track length/total track length), and center time compared to MRL/MPJ mice, suggesting increased risk-seeking behavior (Fig. 3c-e). While the relative center track length was unaltered in hCD20-DTA/MRL/lpr mice compared to MRL/lpr mice (Fig. 3e), center time was significantly reduced (Fig. 3d). Thus, JhD/MRL/lpr mice exhibited enhanced overall motor activity and increased risk-seeking behavior. In contrast, total locomotion activity was unaltered and risk-seeking behavior was decreased in hCD20-DTA/ MRL/lpr mice.

\section{$\mathrm{JhD} / \mathrm{MRL} / \mathrm{pr}$ and hCD20-DTA/MRL/lpr mice exhibit increased BBB permeability}

Disruption of the BBB has been observed in NPSLE patients, as demonstrated by gadolinium contrast-enhanced magnetic resonance imaging [30, 31]. Similarly, extravasation of IgG and other serum proteins into the CNS parenchyma was reported in MRL/lpr mice [32]. Here, we utilized albumin as an indicator of BBB leakage, and found extravasation of albumin predominantly in the cortex, periventricular areas, and cerebellum in the JhD/MRL/lpr, hCD20-DTA/MRL/lpr, and MRL/lpr strains. More than $80 \%$ of mice in each of these strains demonstrated evidence of BBB disruption, as compared to the low baseline in MRL/MPJ mice (Fig. 4a). Similar results were obtained by employing immunofluorescent staining of the brain tissue for fibronectin, another marker for BBB leakage (data not shown).

\section{hCD20-DTA/MRL/Ipr mice display comparable microglial activation to MRL/lpr}

Microglia, as the major phagocytes of the CNS, have an important role in brain surveillance, as well as in homeostatic tissue remodeling and synaptic regulation [33]. With disruption of the BBB, peripheral inflammatory mediators may promote microglial activation. Immunofluorescent staining for Iba-1, a marker of microglial activation, was utilized for the purpose of exploring microglial activation following constitutive $\mathrm{B}$ cell deficiency or postnatal B cell depletion. Interestingly, no differences were observed in microglial activation among MRL/lpr, hCD20-DTA/MRL/lpr, and MRL/MPJ mice. However, JhD/MRL/lpr mice displayed reduced intensity of Iba-1 staining compared to the other three strains (Fig. 4b).

\section{JhD/MRL/lpr and hCD20-DTA/MRL/lpr mice reveal increased} brain cell apoptosis

Cell apoptosis is one striking feature of the MRL/lpr mice brains, and is thought to be one of the underlying causes of the cognitive dysfunction [34, 35]. Thus, we investigated brain cell apoptosis in $B$ cell-deficient and $B$ cell-depleted lupus mice by TUNEL staining. The most common location of TUNEL positive cells in MRL/lpr mice was the periventricular area, as well as among the resident epithelial and the locally infiltrating inflammatory cells in the choroid plexus (Fig. 5a), but not in the hippocampus. Although JhD/MRL/lpr mice possessed significantly fewer TUNEL positive cells than MRL/lpr mice, these were elevated compared to MRL/MPJ (Fig. 5a). Surprisingly, hCD20-DTA/MRL/ lpr mice exhibited significantly higher numbers of TUNEL positive cells, especially in cerebellum, compared to both MRL/lpr and MRL/MPJ mice, perhaps due to the pro-apoptotic properties of tamoxifen [36] (Fig. 5a). Thus, brain cell apoptosis was still present in B cell-deficient and B cell-depleted lupus mice.

\section{hCD20-DTA/MRL/lpr mice exhibit hippocampal astrogliosis}

Astrogliosis, referring to astrocyte proliferation in response to CNS injury, is increased in the hippocampus of MRL/lpr mice [37]. To address whether astrocyte proliferation is affected by B cell deficiency, we examined expression of the astrocyte marker, GFAP, in the brain of JhD/MRL/lpr and hCD20-DTA/MRL/lpr mice. Upregulated hippocampal astrogliosis was observed in hCD20DTA/MRL/lpr mice at a level similar to that found in $\mathrm{MRL} / \mathrm{lpr}$ mice, while astrogliosis was less prominent in JhD/MRL/lpr mice (Fig. 5b). 

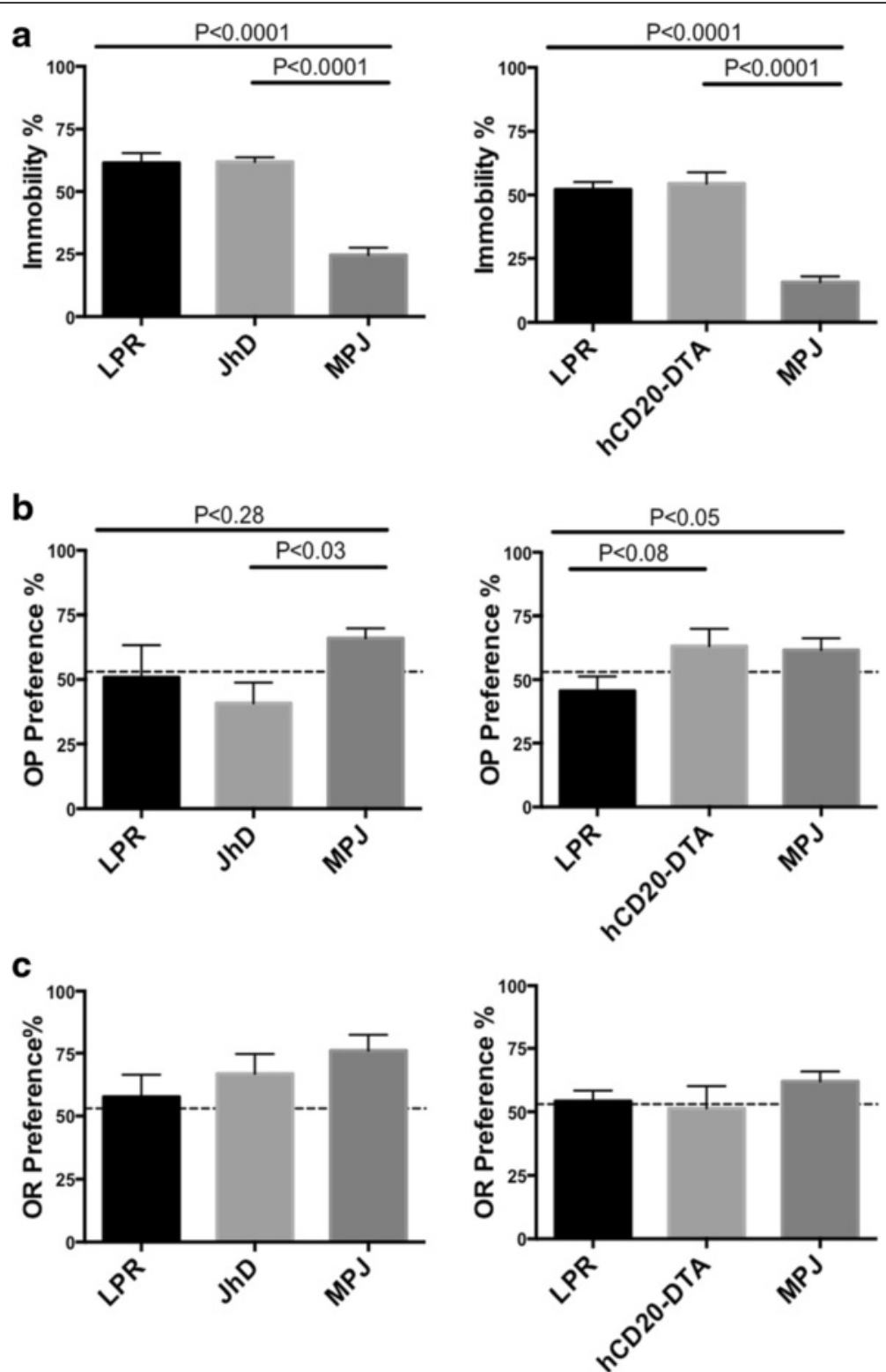

Fig. $2 \mathrm{JhD} / \mathrm{MRL} / \mathrm{lpr}$ and hCD20-DTA/MRL/Ipr mice display depression-like behavior and cognitive dysfunction. The Porsolt swim test (a) was performed to evaluate behavioral despair in JhD/MRL/Ipr and hCD20-DTA/MRL/pr mice. (Left panels: LPR mice, $n=10$; JhD mice, $n=17$; MPJ mice $n=4$; Right panels: LPR mice, $n=7$; hCD20-DTA mice, $n=7$; MPJ mice, $n=12$ ). Object placement (b) and object recognition (c) tests were employed to assess cognitive function in JhD/MRL/Ipr and hCD20-DTA/MRL/Ipr mice. The dotted line indicates $53 \%$ preference score. (Left panels: LPR mice, $n=5$; JhD mice, $n=5$; MPJ mice $n=5$; Right panels: LPR mice, $n=7$; hCD20-DTA mice, $n=7$; MPJ mice, $n=10-11$ ). Since testing affects subsequent performance in neurobehavioral analysis, all behavior tests in a-c were only conducted once. The JhD/MRL/lpr mice were tested at 7-12 weeks of age, and hCD20DTA/MRL/lpr mice at 16-18 weeks of age. The control MRL/pr and MRL/MPJ mice used for comparison were separately age matched to the JhD/ MRL/Ipr and hCD20-DTA/MRL/Ipr strains, respectively

\section{B cell deficiency or depletion in MRL/lpr mice modulates brain cytokine expression}

Since multiple features of the NPSLE phenotype were preserved in JhD/MRL/lpr and hCD20-DTA/MRL/lpr mice, we investigated the effect of $\mathrm{B}$ cell deficiency or depletion on cytokine expression in the brains of lupus mice. Realtime qPCR for selected cytokines associated with SLE and/or NPSLE was carried out, including RANTES, IP-10,
MCP-5, CXCL11, and TNF [19, 38-41]. An approximately two to fourfold suppression in the expression level of these cytokines was detected in brains of JhD/MRL/lpr and hCD20-DTA/MRL/lpr in comparison with MRL/lpr mice (Fig. 6). Nevertheless, RANTES, MCP-5, and IP-10 were still significantly upregulated; as compared to MRL/ MPJ mice, RANTES expression was approximately tenfold, and MCP-5 and IP-10 expression approximately 


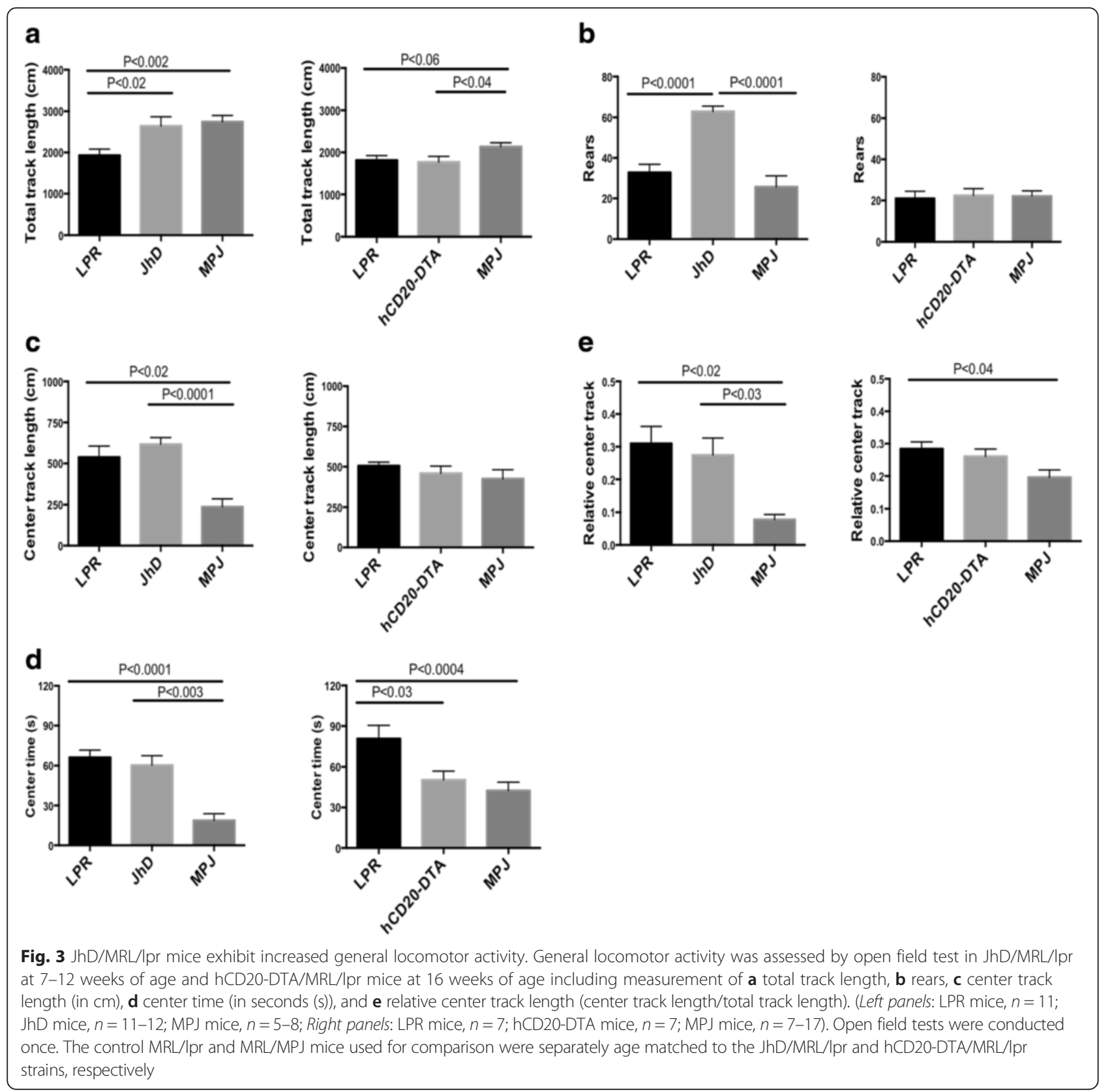

twofold higher. In contrast, the expression of CXCL11 and TNF was reduced to baseline levels in B cell-deficient or B cell-depleted mice (Fig. 6). We also examined the brain mRNA expression of classic interferon signature genes, including IFN $\beta$, IRF7, and IFIT1. However, we found that there were no significant differences in the expression of any of these three genes among MRL/lpr, hCD20-DTA, JhD/MRL/lpr, and MRL/MPJ mice (data not shown). Thus, B cell deficiency or depletion reduced expression of some inflammatory mediators, but other cytokines were generally still expressed in the brains of $\mathrm{JhD} /$ MRL/lpr and hCD20-DTA/MRL/lpr mice at significantly higher levels than in the control MRL/MPJ strain.

\section{Discussion}

In this study, we utilized JhD/MRL/lpr and hCD20DTA/MRL/lpr mouse strains to investigate the role of B cells in the pathogenesis of NPSLE. Autoantibodies and B cells have either been directly linked or closely associated with lupus-associated neuropsychiatric manifestations [4, 42-45]. Evidence supporting the pathogenic role of autoantibodies can be found in studies which demonstrated that lupus-derived IgG autoantibodies directed against NMDAR [28], ribosomal P [46], and phospholipids [47] can induce neurobehavioral deficits, while in human lupus, the association of autoantibodies and neuropsychiatric symptoms has also been suggested 


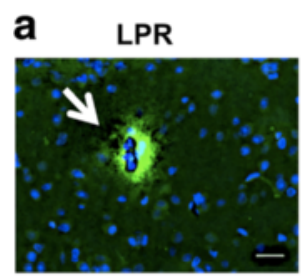

hCD20-DTA
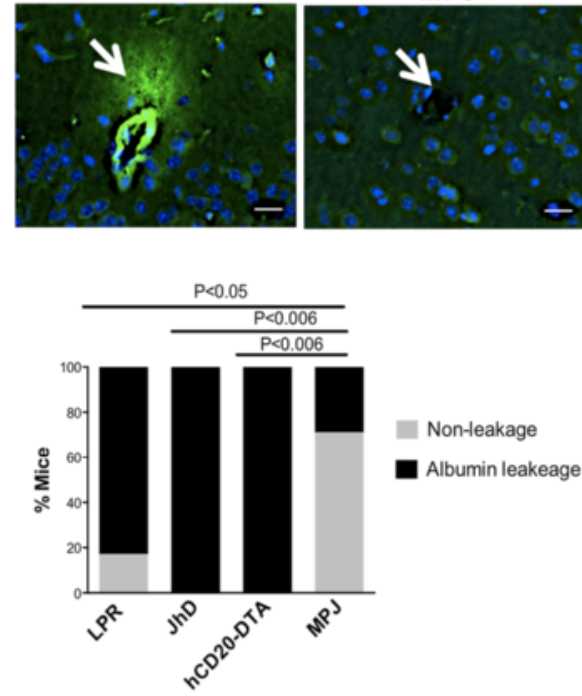

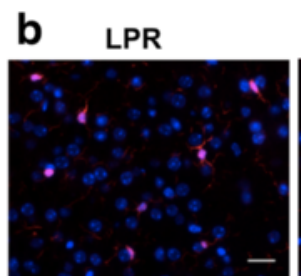

hCD20-DTA
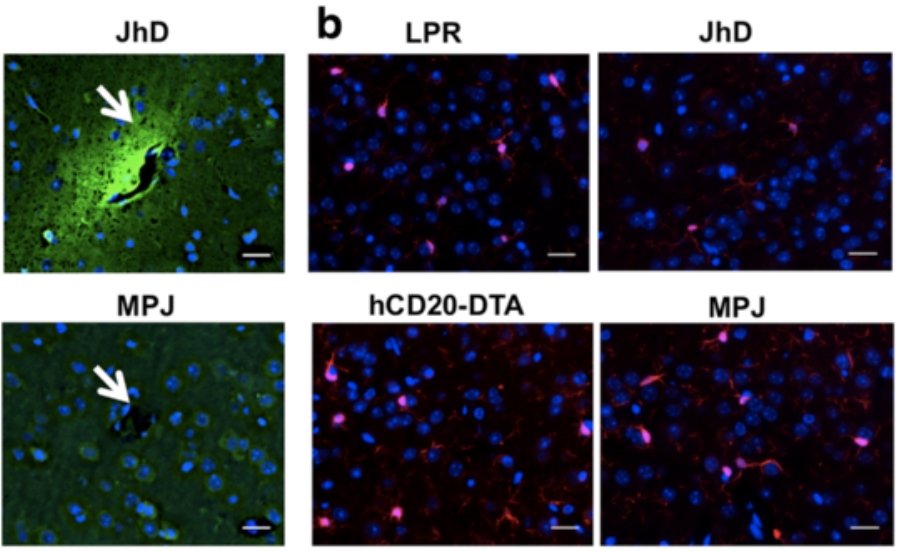

MPJ

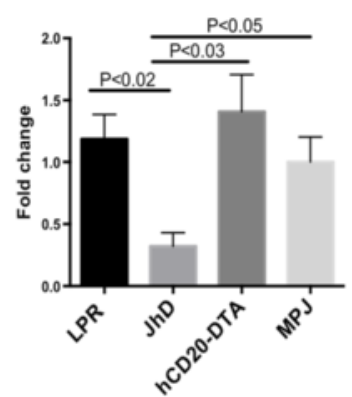

Fig. 4 Blood-brain barrier permeability and microglial activation in B cell-deficient and B cell-depleted lupus mice. a Albumin staining was performed in the brain sections from MRL/Ipr $(n=6)$, JhD/MRL/lpr $(n=4)$, hCD20-DTA/MRL/Ipr $(n=7)$, and MRL/MPJ $(n=7)$ mice, all at 19 weeks of age. Representative images of albumin leakage around the vessels (indicated by arrows) in the cortex are shown. Percentages (\%) of mice in each group that are positive for albumin leakage were displayed. Albumin staining was repeated twice, with similar results. b lba-1 staining was performed on the brain sections of MRL/lpr $(n=6)$, JhD/MRL/lpr $(n=4)$, hCD20-DTAMMR/Ipr $(n=7)$, and MRL/MPJ ( $n=7)$ mice, all at 19 weeks of age. Representative images of Iba-1 staining in the cortex are shown. Fold changes of fluorescence intensity are shown in the bottom panel, with the mean of MRL/MPJ set at 1. Iba-1 staining was repeated twice, with similar results. The scale bar in each image represents 20 um

by numerous studies [6]. Contrary to our expectations, however, we found that $\mathrm{B}$ cell deficiency or depletion does not ameliorate key manifestations of NPSLE, including depression-like behavior and cognitive dysfunction. Our findings therefore strongly suggest that B cells or circulating antibodies are not strictly required to fully reproduce the NPSLE phenotype.

Since B cell depletion required testing the mice when they were no longer young, any potential confounding effect of age on the behavioral phenotype needs to be considered. Nevertheless, while the wild-type and B celldepleted MRL/lpr mice float excessively (>50\%) at 4 months of age, the age matched control MRL/MPJ mice displayed minimal floating $(\sim 16 \%)$. Indeed, the lupus mice in our current study floated much more than older C57BL/6 mice tested previously (historical controls; data not shown). Thus, the reasonable conclusion would be that age did not significantly affect mobility in the swim test. Similarly in the other behavior tests as well, all animals are age matched, and therefore any possible effects of age were properly controlled for.
It is important nevertheless to note that B celldeficient or B cell-depleted mice did not always display the same phenotype. In the neurobehavioral testing, JhD/MRL/lpr mice exhibited deficient spatial memory and increased total track length, while the hCD20-DTA/ MRL/lpr displayed abnormal visual memory but preserved total track length. Furthermore, histopathological features characterizing the unmanipulated MRL/lpr strain including microglial activation, brain cell apoptosis, and astrogliosis were more prominent in the hCD20-DTA/MRL/lpr strain. This divergence can be explained by the different timing (i.e., congenital depletion) and relative completeness of B cell depletion (Fig. 1) occurring in the JhD/MRL/lpr strain. Furthermore, even though the brains from both strains were studied at the same age, the neurobehavioral assessment of hCD20DTA/MRL/lpr was delayed by a few weeks due to tamoxifen administration. Indeed, some of the pathology observed in the hCD20-DTA/MRL/lpr strain could have been induced prior to administration of tamoxifen, or even after $B$ cell depletion since autoantibodies did not 


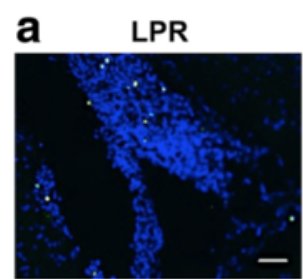

hCD20-DTA

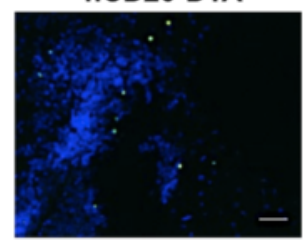

JhD

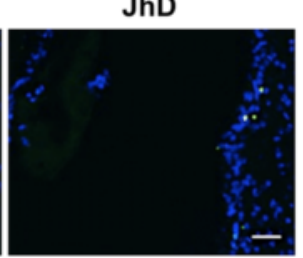

MPJ
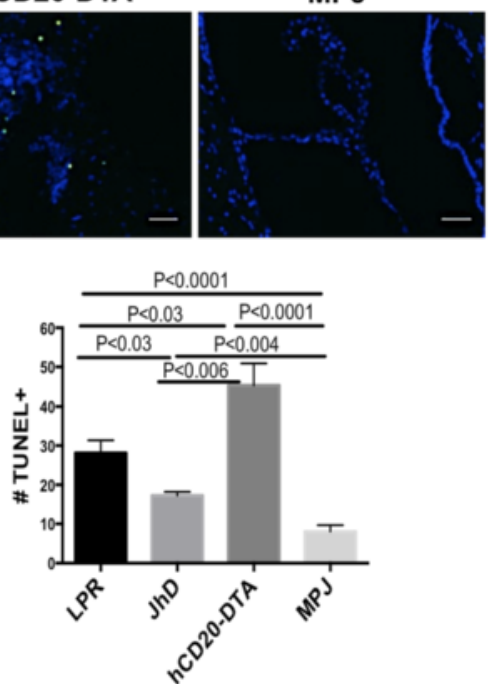

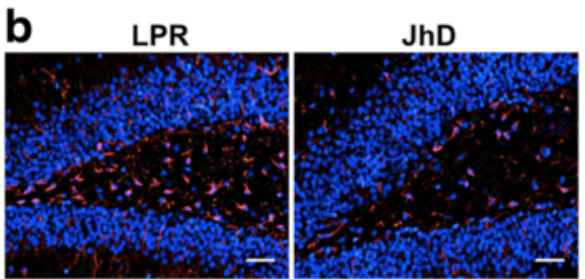

hCD20-DTA
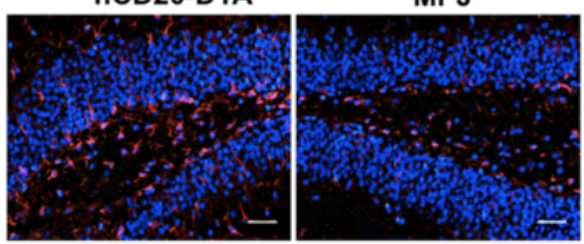

MPJ

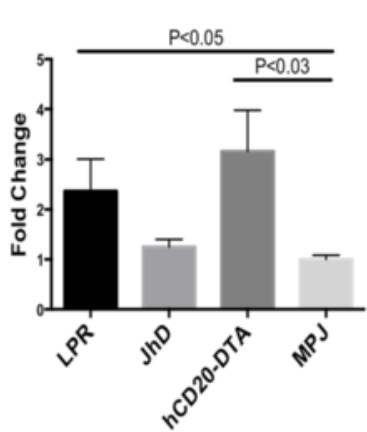

Fig. 5 Brain cell apoptosis and hippocampal gliosis in JhD/MRL/lpr and hCD20-DTA/MRL/lpr mice. TUNEL and GFAP staining was performed in MRL/Ipr $(n=6)$, JhD/MRL/Ipr $(n=4)$, hCD20-DTA/MRL/Ipr $(n=7)$, and MRL/MPJ $(n=7)$ mice, all at 19 weeks of age. Representative images of TUNEL staining in periventricular areas and choroid plexus are shown in (a, top pane/s). Quantitation of the average number of TUNEL positive cells in the two brain sections from each mouse is indicated in the bottom panel. b Representative images of GFAP staining in the hippocampus. Fold changes of fluorescence intensity are shown in the bottom panel, with the mean of MRL/MPJ set at 1. TUNEL and GFAP staining were repeated twice, with similar results. The scale bar in each image represents $40 \mu \mathrm{m}$

totally disappear in this strain. Nevertheless, several key important features of the neuropsychiatric phenotype of murine (and human) lupus, including depression-like behavior (Fig. 2a) and permeabilization of the BBB (Fig. 4a), persisted despite $\mathrm{B}$ cell depletion and did not differ between the JhD/MRL/lpr and hCD20-DTA/MRL/ lpr strains. We believe that the concurrence of these two features is not coincidental, as disruption of the neurovascular unit has been linked to non-lupus-related major depressive disorder as well [48]. Persistence of at least some of central features of murine NPSLE despite a marked reduction in, or ablation of, B cells and autoantibodies is an unexpected finding, which we believe is reported here for the first time. Nevertheless, certain histopathological features did variably improve, and cytokine expression was attenuated in B cell deficient mice, indicating that $\mathrm{B}$ cells and/or autoantibodies do affect the brain, albeit not in disrupting the BBB or contributing to depression-like behavior. Furthermore, we believe that another interesting and potentially revealing avenue for future studies will indeed be in attempting to understand the behavioral and pathophysiologic (e.g., microglial activation, brain cell apoptosis) differences between lupus mice with constitutive absence of B cells as compared to those with B cells depleted in later life.

The immune system plays a crucial role in cognition [49-51]. Microglia, as the major immune cells in the brain, function as phagocytes to clear cell debris and maintain surveillance and homeostasis in the central nervous system. Microglia, together with T cells, are implicated in hippocampal neurogenesis and spatial memory $[52,53]$. Mice deprived of mature $\mathrm{T}$ cells displayed impaired hippocampal neurogenesis and cognitive dysfunction, which can be reversed by restoring $\mathrm{T}$ cells that recognized a specific brain antigen [53]. Furthermore, antibodies have been shown to affect brain growth and development [54]. Thus, although we are not aware of any direct evidence defining the role of endogenous $B$ cells during development on cognition, these cells can possibly influence future cognitive function, either directly or through their interaction with other immune cells. We speculate that this might be one possible cause for the partial dependence of the neurobehavioral phenotype on the timing of $\mathrm{B}$ cell depletion. 


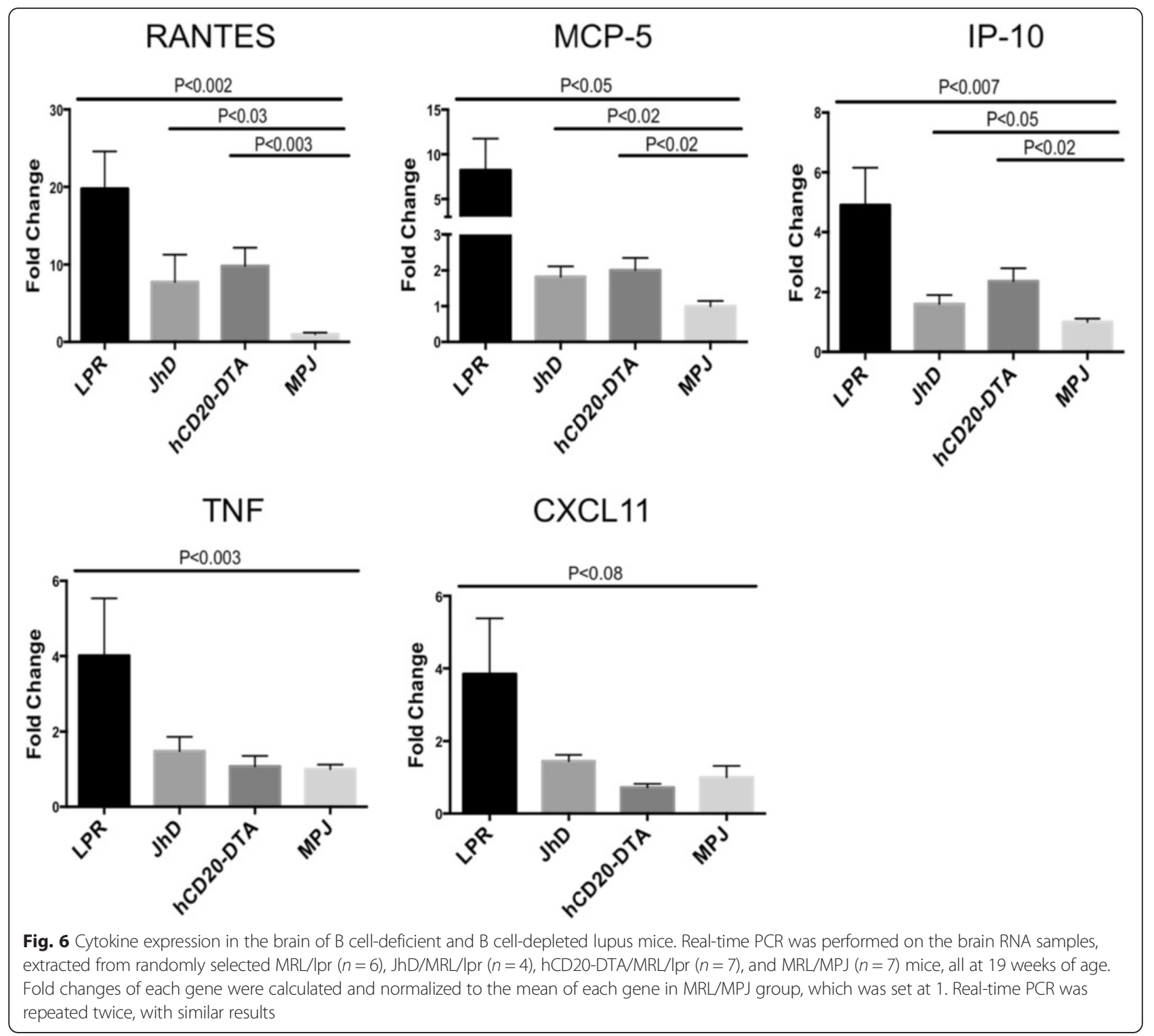

The role autoantibodies play in the pathogenesis of NPSLE has yet to be fully clarified. Multiple brain reactive and non-brain specific antibodies are associated with NPSLE [6]. Anti-cardiolipin autoantibodies and lupus anticoagulant in particular have been strongly associated with cerebrovascular disease; anti-ribosomal P antibodies correlate with lupus psychosis, and anti-NMDA receptor antibodies have been associated with diffuse NPSLE manifestations [55]. This diversity in autoantibody specificities associated with NPSLE may represent the varied and complex nature of NPSLE manifestations, which plausibly can be related to multiple different autoantibodies. However, although some encouraging results were observed in clinical trials of NPSLE patients with the $B$ cell-depleting therapy rituximab $[56,57]$, these studies only included a relatively small number of patients and were uncontrolled. Thus, the efficacy of rituximab as a therapeutic approach for NPSLE patients remains to be determined [57].

In murine models, several studies have demonstrated that autoantibodies can bind to brain specific antigens, inducing lupus-like pathologic behavior. Katzav et al. found that anti-ribosomal $\mathrm{P}$ antibodies deposited in the limbic system (piriform cortex, hippocampus, and cingulate cortex) can produce depression-like behavior [46] Similarly, a recent study showed that anti-ribosomal P antibodies purified from NPSLE patients bound to hippocampal neurons in the brains of healthy mice, leading to memory impairment [29]. Moreover, Kowal et al. demonstrated that following compromise of the $\mathrm{BBB}$, anti-NMDA receptor antibodies can induce neuronal cell death resulting in cognitive dysfunction [28]. 
Specifically, these antibodies induced apoptosis in the CA1 region of the hippocampus [28]. Nevertheless, to our surprise, we found that B cell-deficient and B celldepleted MRL/lpr mice continued to exhibit features of the characteristic NPSLE phenotype of this strain. Both JhD/MRL/lpr and hCD20-DTA/MRL/lpr mice demonstrated depression-like behavior and cognitive deficits similar to unmanipulated MRL/lpr mice, as well as BBB disruption, brain cell apoptosis, and cytokine upregulation. This observation can be explained in several ways. First, although the abrogation of BBB may indeed be a prerequisite for autoantibodies to access the brain, the opening of $\mathrm{BBB}$ is usually transient, and eventually, the autoantibodies that bypass the BBB play a less important role in disease initiation than other inflammatory mediators within the CNS. Second, the strains of mice were different; autoimmune MRL/lpr mice (a strain with spontaneous disease and thus more similar to human SLE) are characterized by a complex dysregulation of cytokines and antibodies, while previous studies addressing the role of pathogenic antibodies in murine NPSLE used non-autoimmune strains, and tested whether manipulations elicited acute behavioral or histologic alterations.

We found that disruption of the BBB persisted despite acute B cell deficiency or depletion. This breached BBB can trigger an inflammatory cascade, modulating astrocyteneuron crosstalk and altering the release of neurotransmitters, which may have contributed to the observed behavioral abnormalities. Increased brain cell apoptosis among JhD/MRL/lpr, hCD20-DTA/MRL/lpr, and MRL/lpr mice may be another consequence of $\mathrm{BBB}$ disruption. While the more marked apoptosis observed in the hCD20DTA as compared to the JhD/MRL/lpr strain may have been contributed by tamoxifen [36], the fact that both MRL/lpr and to a lesser degree JhD/MRL/lpr had significantly increased brain cell apoptosis as compared to the MRL/MPJ mice suggests that this process is a characteristic of (if not a contributor to) NPSLE in this strain, which is not eliminated by a reduction in the numbers of B cells.

The role of cytokines in NPSLE is supported by numerous studies. Although SLE is characterized by high titers of autoantibodies, the onset of NPSLE can occur at any stage of the disease, even prior to a significant rise in autoantibody titers [15]. Furthermore, the severity of NPSLE may not correlate with autoantibody titers [58]. MRL/lpr mice develop depression-like behavior before the peak of autoantibody production or evidence of systemic disease [19]. Cytokine dysregulation, however, occurs as early as 1-4 weeks of age [59-62]. We found decreased expression of RANTES, MCP-5, IP-10, CXCL11, and TNF following B cell deficiency or depletion in MRL/ lpr mice. Nevertheless, at least RANTES, MCP-5, and IP10 remained significantly elevated in $\mathrm{B}$ cell-deficient and $\mathrm{B}$ cell-depleted mice in comparison with MRL/MPJ mice.
This observation suggests that these cytokines (or others not tested for), probably derived from CNS resident cells such as astrocytes and microglia, may actually be the key effectors in initiating the pathogenesis of NPSLE-at least in the absence of B cells and/or autoantibodies. This observation is consistent with several clinical studies that found that increased levels of RANTES, IP-10, and MCP-5 in the CSF correlate with NPSLE manifestations [38-41]. Furthermore, the persistence of the NPSLE phenotype in JhD/MRL/lpr and hCD20-DTA/MRL/lpr mice may indicate that mood and cognition are very sensitive to cytokine abnormalities, and therefore, a robust NPSLE phenotype is manifested even with lower brain cytokine levels than in the MRL/lpr strain.

Besides the role cytokines play in CNS abnormalities, other potential contributors may also need to be taken into consideration. Long-lived plasma cells secreting autoantibodies are resistant to B cell depletion [10]; however, these would be absent in the $\mathrm{B}$ cell-deficient strain (JhD/MRL/lpr), and thus, these plasma cells are unlikely to be the early mediators of NPSLE. Additionally, Chan et al. reported that although tenfold reductions in $\mathrm{CD}^{+}$and $\mathrm{CD}^{+} \mathrm{T}$ cells were observed in B cell-deficient mice (JhD/MRL/lpr), a few $\mathrm{T}$ cells were persistent [18], suggesting a potential role for $\mathrm{T}$ cells as well. Furthermore, gut microbiota has recently been suggested to be involved in brain function including anxiety, mood, cognition, and pain [63]. Therefore, whether B cell deficiency or depletion modulates gut microbiota will be an interesting question to explore. Finally, Fas and Fas ligand are expressed in the CNS, and one may ask whether the neuropsychiatric symptoms seen in MRL/lpr mice are mediated by abnormal Fas signaling [64], for example, by altering apoptosis in microglia and/or other brain cell types. Nevertheless, since NPSLE manifestations also appear in other, non-Fas-mediated murine lupus models [9], autoimmunity is the most likely mechanistic explanation in the MRL/lpr model as well.

Thus, there are several potential mechanisms to explain the persistence of neuropsychiatric lupus in MRL/lpr mice despite a significant decrease in, or depletion of, B cells and autoantibodies, including pathways involving cytokines, microglial activation, neurotransmitters, etc. We acknowledge that while the differential effects on cytokines reported above are interesting, these studies are preliminary. Moreover, the additional possible mechanisms will need to be further explored. Indeed, considering the complex immune abnormalities present in SLE, we believe that the neurobehavioral deficits seen in murine lupus strains (and in human disease) are most likely due to the combined contributions of more than a single mechanism. The lack of strict dependence of neuropsychiatric lupus on the presence of B cells and autoantibodies is nonetheless a novel and surprising observation, and 
additional investigation outside the scope of the present study will be required in the future to continue to define the relevant molecular pathways.

\section{Conclusions}

Our data collectively indicate that lack of B cells and autoantibodies in MRL/lpr mice does not prevent the development of key features of NPSLE; this is most convincingly shown by the neurobehavioral deficits observed in $\mathrm{JhD} /$ MRL/lpr mice that lacked B cells from birth. Furthermore, among the cytokines studied, we found that RANTES, IP10 , and MCP- 5 were persistently elevated in B cell-deficient and B cell-depleted MRL/lpr mice, suggesting a possible role as effectors of NPSLE pathogenesis. Future studies can include a more comprehensive characterization of the cytokines produced in B cell-deficient and B cell-depleted mice and identification of their cellular origins within the CNS, and further exploration of the contribution of $\mathrm{T}$ cells and microbiota. It will be interesting to test whether intracerebral cytokine administration alone can induce a NPSLE-like phenotype. If in fact that is the case, such a mediator may provide a valuable therapeutic target for this challenging lupus end-organ manifestation.

\section{Competing interests}

The authors declare that they have no competing interests.

\section{Authors' contributions}

JW performed the majority of the experiments, aided in the experimental design, and wrote the initial version of the manuscript. JD, SC, and AS aided in phenotypic characterization. HW assisted with the generation and care of the experimental animals. MG assisted with behavioral testing design and data analysis. MJS assisted in study design and analysis. CP designed the study, edited and provided final approval of this manuscript. All authors read and approved the final manuscript.

\section{Acknowledgements}

These studies were supported by research grants from the NIH (AR065594) and the Lupus Research Institute to C. Putterman, and the National Institutes of Health (AR044077) to M. Shlomchik.

\section{Author details \\ ${ }^{1}$ Department of Microbiology and Immunology, Albert Einstein College of Medicine, Bronx, NY, USA. ${ }^{2}$ Department of Immunobiology, Yale University, New Haven, CT, USA. 'B Behavioral Core Facility, Department of Neuroscience, Albert Einstein College of Medicine, Bronx, NY, USA. ${ }^{4}$ Department of Immunology, University of Pittsburgh, Pittsburgh, PA, USA. ${ }^{5}$ Division of Rheumatology, Albert Einstein College of Medicine, F701N, 1300 Morris Park Ave, Bronx, NY 10461, USA.}

Received: 1 December 2015 Accepted: 31 March 2016 Published online: 07 April 2016

\section{References}

1. Stock AD, Wen J, Putterman C. Neuropsychiatric lupus, the blood brain barrier, and the TWEAK/Fn14 pathway. Front Immunol. 2013;4:484.

2. Bertsias GK, Boumpas DT. Pathogenesis, diagnosis and management of neuropsychiatric SLE manifestations. Nat Rev Rheumatol. 2010;6:358-67.

3. Hanly JG. Diagnosis and management of neuropsychiatric SLE. Nat Rev Rheumatol. 2014;10:338-47.

4. Kivity S, Agmon-Levin N, Zandman-Goddard G, Chapman J, Shoenfeld Y Neuropsychiatric lupus: a mosaic of clinical presentations. BMC Med. 2015;13:43.

5. Gulinello M, Wen J, Putterman C. Neuropsychiatric symptoms in lupus. Psychiatr Ann. 2012;42:322-8.
6. Sciascia S, Bertolaccini ML, Roccatello D, Khamashta MA, Sanna G. Autoantibodies involved in neuropsychiatric manifestations associated with systemic lupus erythematosus: a systematic review. J Neurol. 2014;261:1706-14.

7. Fanouriakis A, Boumpas DT, Bertsias GK. Pathogenesis and treatment of CNS lupus. Curr Opin Rheumatol. 2013;25:577-83.

8. Cobo-Ibanez T, Loza-Santamaria E, Pego-Reigosa JM, Marques AO, RuaFigueroa I, Fernandez-Nebro A, et al. Efficacy and safety of rituximab in the treatment of non-renal systemic lupus erythematosus: a systematic review. Semin Arthritis Rheum. 2014;44:175-85.

9. Gulinello M, Putterman C. The MRL/Ipr mouse strain as a model for neuropsychiatric systemic lupus erythematosus. J Biomed Biotechnol. 2011; 2011:207504.

10. Ahuja A, Shupe J, Dunn R, Kashgarian M, Kehry MR, Shlomchik MJ. Depletion of B cells in murine lupus: efficacy and resistance. J Immunol. 2007;179:3351-61

11. Chan OT, Madaio MP, Shlomchik MJ. B cells are required for lupus nephritis in the polygenic, Fas-intact MRL model of systemic autoimmunity. J Immunol. 1999;163:3592-6.

12. Khalil AM, Cambier JC, Shlomchik MJ. B cell receptor signal transduction in the GC is short-circuited by high phosphatase activity. Science. 2012;336:1178-81.

13. Teichmann LL, Ols ML, Kashgarian M, Reizis B, Kaplan DH, Shlomchik MJ. Dendritic cells in lupus are not required for activation of $T$ and $B$ cells but promote their expansion, resulting in tissue damage. Immunity. 2010;33:967-78.

14. Ivanova A, Signore M, Caro N, Greene ND, Copp AJ, Martinez-Barbera JP. In vivo genetic ablation by Cre-mediated expression of diphtheria toxin fragment A. Genesis. 2005;43:129-35.

15. Gao HX, Campbell SR, Cui MH, Zong P, Hee-Hwang J, Gulinello M, et al. Depression is an early disease manifestation in lupus-prone MRL/Ipr mice. J Neuroimmunol. 2009;207:45-56.

16. Sakic B. The MRL model: an invaluable tool in studies of autoimmunity-brain interactions. Methods Mol Biol. 2012;934:277-99.

17. Li Y, Eskelund AR, Zhou H, Budac DP, Sanchez C, Gulinello M. Behavioral deficits are accompanied by immunological and neurochemical changes in a mouse model for neuropsychiatric lupus (NP-SLE). Int J Mol Sci. 2015;16:15150-71.

18. Chan O, Shlomchik MJ. A new role for B cells in systemic autoimmunity: B cells promote spontaneous T cell activation in MRL-lpr/lpr mice. J Immunol. 1998;160:51-9.

19. Wen J, Xia Y, Stock A, Michaelson JS, Burkly LC, Gulinello M, et al. Neuropsychiatric disease in murine lupus is dependent on the TWEAK/Fn14 pathway. J Autoimmun. 2013:43:44-54.

20. Kowal C, Diamond B. Aspects of CNS lupus: mouse models of anti-NMDA receptor antibody mediated reactivity. Methods Mol Biol. 2012;900:181-206.

21. Gono T, Kawaguchi Y, Kaneko H, Nishimura K, Hanaoka M, Kataoka S, et al. Anti-NR2A antibody as a predictor for neuropsychiatric systemic lupus erythematosus. Rheumatology (Oxford). 2011;50:1578-85.

22. Steup-Beekman G, Steens S, van Buchem M, Huizinga T. Anti-NMDA receptor autoantibodies in patients with systemic lupus erythematosus and their first-degree relatives. Lupus. 2007;16:329-34.

23. Ogawa E, Nagai T, Sakuma Y, Arinuma Y, Hirohata S. Association of antibodies to the NR1 subunit of N-methyl-D-aspartate receptors with neuropsychiatric systemic lupus erythematosus. Mod Rheumatol. 2015:1-7. [Epub ahead of print].

24. Cole PD, Vijayanathan V, Ali NF, Wagshul ME, Tanenbaum EJ, Price J, et al. Memantine protects rats treated with intrathecal methotrexate from developing spatial memory deficits. Clin Cancer Res. 2013;19:4446-54.

25. Li Y, Vijayanathan V, Gulinello ME, Cole PD. Systemic methotrexate induces spatial memory deficits and depletes cerebrospinal fluid folate in rats. Pharmacol Biochem Behav. 2010;94:454-63.

26. Wen J, Doerner J, Weidenheim K, Xia Y, Stock A, Michaelson JS, et al. TNFlike weak inducer of apoptosis promotes blood brain barrier disruption and increases neuronal cell death in MRL/lpr mice. J Autoimmun. 2015;60: 40-50.

27. Stanojcic M, Loheswaran G, Xu L, Hoffman SA, Sakic B. Intrathecal antibodies and brain damage in autoimmune MRL mice. Brain Behav Immun. 2010;24:289-97.

28. Kowal C, Degiorgio LA, Lee JY, Edgar MA, Huerta PT, Volpe BT, et al. Human lupus autoantibodies against NMDA receptors mediate cognitive impairment. Proc Natl Acad Sci U S A. 2006;103:19854-9.

29. Bravo-Zehnder M, Toledo EM, Segovia-Miranda F, Serrano FG, Benito MJ Metz C, et al. Anti-ribosomal p protein autoantibodies from patients with neuropsychiatric lupus impair memory in mice. Arthritis Rheumatol. 2015;67: 204-14. 
30. Hughes M, Sundgren PC, Fan X, Foerster B, Nan B, Welsh RC, et al. Diffusion tensor imaging in patients with acute onset of neuropsychiatric systemic lupus erythematosus: a prospective study of apparent diffusion coefficient, fractional anisotropy values, and eigenvalues in different regions of the brain. Acta Radiol. 2007;48:213-22.

31. Abbott NJ, Mendonca LL, Dolman DE. The blood-brain barrier in systemic lupus erythematosus. Lupus. 2003;12:908-15.

32. Alexander JJ, Jacob A, Vezina P, Sekine H, Gilkeson GS, Quigg RJ. Absence of functional alternative complement pathway alleviates lupus cerebritis. Eur J Immunol. 2007;37:1691-701.

33. Derecki NC, Cronk JC, Kipnis J. The role of microglia in brain maintenance: implications for Rett syndrome. Trends Immunol. 2013;34:144-50.

34. Ballok DA, Millward JM, Sakic B. Neurodegeneration in autoimmune MRL-Ipr mice as revealed by Fluoro Jade B staining. Brain Res. 2003;964: 200-10.

35. Alexander JJ, Jacob A, Bao L, Macdonald RL, Quigg RJ. Complementdependent apoptosis and inflammatory gene changes in murine lupus cerebritis. J Immunol. 2005;175:8312-9.

36. Mandlekar S, Kong AN. Mechanisms of tamoxifen-induced apoptosis. Apoptosis. 2001;6:469-77.

37. Ballok DA, Woulfe J, Sur M, Cyr M, Sakic B. Hippocampal damage in mouse and human forms of systemic autoimmune disease. Hippocampus. 2004;14:649-61.

38. Perry D, Sang A, Yin Y, Zheng YY, Morel L. Murine models of systemic lupus erythematosus. J Biomed Biotechnol. 2011;2011:271694.

39. Fragoso-Loyo H, Richaud-Patin Y, Orozco-Narvaez A, Davila-Maldonado L, Atisha-Fregoso Y, Llorente L, et al. Interleukin-6 and chemokines in the neuropsychiatric manifestations of systemic lupus erythematosus. Arthritis Rheum. 2007:56:1242-50.

40. Fragoso-Loyo H, Atisha-Fregoso Y, Llorente L, Sanchez-Guerrero J. Inflammatory profile in cerebrospinal fluid of patients with headache as a manifestation of neuropsychiatric systemic lupus erythematosus. Rheumatology (Oxford). 2013:52:2218-22.

41. Okamoto H, Katsumata Y, Nishimura K, Kamatani N. Interferon-inducible protein 10/CXCL10 is increased in the cerebrospinal fluid of patients with central nervous system lupus. Arthritis Rheum. 2004;50:3731-2.

42. Unterman A, Nolte JE, Boaz M, Abady M, Shoenfeld Y, Zandman-Goddard G Neuropsychiatric syndromes in systemic lupus erythematosus: a metaanalysis. Semin Arthritis Rheum. 2011:41:1-11.

43. Sherer Y, Gorstein A, Fritzler MJ, Shoenfeld Y. Autoantibody explosion in systemic lupus erythematosus: more than 100 different antibodies found in SLE patients. Semin Arthritis Rheum. 2004;34:501-37.

44. Zameer A, Hoffman SA. Immunoglobulin binding to brain in autoimmune mice. J Neuroimmunol. 2001;120:10-8.

45. Zameer A, Hoffman SA. B and T cells in the brains of autoimmune mice. J Neuroimmunol. 2004;146:133-9.

46. Katzav A, Solodeev I, Brodsky O, Chapman J, Pick CG, Blank M, et al. Induction of autoimmune depression in mice by anti-ribosomal $\mathrm{P}$ antibodies via the limbic system. Arthritis Rheum. 2007;56:938-48.

47. Gharavi AE, Pierangeli SS, Espinola RG, Liu X, Colden-Stanfield M, Harris EN. Antiphospholipid antibodies induced in mice by immunization with a cytomegalovirus-derived peptide cause thrombosis and activation of endothelial cells in vivo. Arthritis Rheum. 2002;46:545-52.

48. Najjar S, Pearlman DM, Devinsky O, Najjar A, Zagzag D. Neurovascular unit dysfunction with blood-brain barrier hyperpermeability contributes to major depressive disorder: a review of clinical and experimental evidence. J Neuroinflammation. 2013;10:142.

49. Marin I, Kipnis J. Learning and memory ... the immune system. Learn Mem. 2013:20:601-6.

50. Dunn-Walters DK, Edelman H, Mehr R. Immune system learning and memory quantified by graphical analysis of B-lymphocyte phylogenetic trees. Biosystems. 2004;76:141-55.

51. Hiramoto RN, Rogers CF, Demissie S, Hsueh CM, Hiramoto NS, Lorden JF, et al. Psychoneuroendocrine immunology: site of recognition, learning and memory in the immune system and the brain. Int J Neurosci. 1997:92:259-85.

52. Gemma C, Bachstetter AD. The role of microglia in adult hippocampal neurogenesis. Front Cell Neurosci. 2013;7:229.

53. Ziv Y, Ron N, Butovsky O, Landa G, Sudai E, Greenberg N, et al. Immune cells contribute to the maintenance of neurogenesis and spatial learning abilities in adulthood. Nat Neurosci. 2006;9:268-75.

54. Bauman MD, losif AM, Ashwood P, Braunschweig D, Lee A, Schumann CM, et al. Maternal antibodies from mothers of children with autism alter brain growth and social behavior development in the rhesus monkey. Transl Psychiatry. 2013;3:e278

55. Arinuma Y, Yanagida T, Hirohata S. Association of cerebrospinal fluid antiNR2 glutamate receptor antibodies with diffuse neuropsychiatric systemic lupus erythematosus. Arthritis Rheum. 2008;58:1130-5.

56. Tokunaga M, Saito K, Kawabata D, Imura Y, Fujii T, Nakayamada S, et al. Efficacy of rituximab (anti-CD20) for refractory systemic lupus erythematosus involving the central nervous system. Ann Rheum Dis. 2007;66:470-5.

57. Eko SL, van Vollenhoven RF. Rituximab and lupus - a promising pair? Curr Rheumatol Rep. 2014;16:444.

58. Sakic B, Hanna SE, Millward JM. Behavioral heterogeneity in an animal model of neuropsychiatric lupus. Biol Psychiatry. 2005;57:679-87.

59. Alleva DG, Kaser SB, Beller DI. Aberrant cytokine expression and autocrine regulation characterize macrophages from young MRL+/+ and NZB/W F1 lupus-prone mice. J Immunol. 1997:159:5610-9.

60. Suzuki H, Yasukawa K, Saito T, Narazaki M, Hasegawa A, Taga T, et al. Serum soluble interleukin-6 receptor in MRL/lpr mice is elevated with age and mediates the interleukin-6 signal. Eur J Immunol. 1993;23:1078-82.

61. Altman A, Theofilopoulos AN, Weiner R, Katz DH, Dixon FJ. Analysis of T cell function in autoimmune murine strains. Defects in production and responsiveness to interleukin 2. J Exp Med. 1981;154:791-808.

62. Sakic B, Szechtman H, Braciak T, Richards C, Gauldie J, Denburg JA. Reduced preference for sucrose in autoimmune mice: a possible role of interleukin- 6 . Brain Res Bull. 1997:44:155-65.

63. Cryan JF, Dinan TG. Mind-altering microorganisms: the impact of the gut microbiota on brain and behaviour. Nat Rev Neurosci. 2012;13:701-12.

64. Choi C, Benveniste EN. Fas ligand/Fas system in the brain: regulator of immune and apoptotic responses. Brain Res Brain Res Rev. 2004:44:65-81.

\section{Submit your next manuscript to BioMed Central and we will help you at every step:}

- We accept pre-submission inquiries

- Our selector tool helps you to find the most relevant journal

- We provide round the clock customer support

- Convenient online submission

- Thorough peer review

- Inclusion in PubMed and all major indexing services

- Maximum visibility for your research

Submit your manuscript at www.biomedcentral.com/submit

Biomed Central 